This is the post-print version of an article published in Assessment \& Evaluation in Higher Education. Please cite this article as follows:

Lambrechts, Wim (2015). The contribution of sustainability assessment to policy development in higher education. Assessment \& Evaluation in Higher Education, Vol. 40 (6), pp. 801-816.

To link to this article: $\underline{\text { http://dx.doi.org/10.1080/02602938.2015.1040719 }}$

\title{
The contribution of sustainability assessment to policy development in higher education
}

Wim Lambrechts

Department of Business Studies, Leuven University College (KHLeuven), Leuven, Belgium Department of Philosophy, University of Antwerp (UA), Antwerp, Belgium

E-mail address: wim@lambrechts.org, website: www.sustainablehighereducation.com

Wim Lambrechts is holder of a Special PhD Fellowship of the Research Foundation -

Flanders (FWO). His research focuses on the integration of sustainable development in higher education, with specific attention towards competences for sustainable development; indicators and assessment instruments for sustainability; and implementation models. He was also involved in the very first Belgian project on Sustainability Assessment in higher education and the use of AISHE. 


\begin{abstract}
This article builds upon the experiences and results of the application of sustainability assessment instruments in higher education. First, a short overview of existing sustainability assessment tools will be provided, as well as their contribution towards the integration of sustainability in higher education. Second, a reflective case focuses on the use of sustainability assessment for policy development in higher education. This case is based upon the application of the Auditing Instrument for Sustainability in Higher Education (AISHE) in a Belgian higher education institution, focusing on four consecutive assessments in the department of Business Studies (2003, 2004, 2009, 2010). Based on the assessment reports and an evaluation of the assessments, the contribution of sustainability assessment to policy development is reflected upon. The article provides a research-based, reflective study, and focuses on the consecutive application of sustainability assessment tools (i.e. more than 1 ad-hoc initiative); the contribution of sustainability assessment to policy development (i.e. defining a sustainability vision, drafting a sustainability policy plan, defining indicators to follow-up); the contribution of sustainability assessment to connecting a bottom-up approach to a top-down approach. The article results in specific recommendations on the use of sustainability assessment for policy development in higher education.
\end{abstract}

Keywords: Sustainable higher education; sustainability assessment; policy development; AISHE

\title{
Introduction
}

Higher education institutions bear a profound societal responsibility, i.e. contributing to the transition process towards sustainable development. This responsibility is derived from the so called 'wicked problems' in society, and the inability of societal stakeholders to find answers to these problems (Rieckmann 2012; Wiek, Withycombe, and Redman 2011). Higher education institutions are expected to help students acquire the competences that enable them to cope with these problems and find sustainable solutions, however the integration of these competences for sustainable development remains fragmented and implicit (Lambrechts et al. 2013). Furthermore, as a part of their societal responsibility, Higher education institutions are ought to lead by example, and thus integrate sustainability principles within their campus 
operations, research and outreach. This approach, where sustainability integration is encouraged within all working fields of higher education, is envisioned within numerous charters and declarations for sustainability in higher education (Lozano et al. 2013; Wright 2004). To enable higher education institutions to follow up their own initiatives to integrate sustainable development, sustainability assessment has become -or should become- an inevitable part of these working fields (Lozano et al. 2013), however results from a worldwide survey show that sustainability assessment is lagging behind in higher education institutions' practices (Lozano et al. 2015, in press).

Regarding sustainability assessment in higher education, a lot of attention has been given towards the development of criteria, indicators, tools and instruments. The variety of approaches to apply sustainability indicators in higher education institutions is abundant, and covers conceptual frameworks, environmental management systems, reporting guidelines, life cycle assessments, ranking tools, indexes, etc. (Ramos and Pires 2013). Specifically focusing on sustainability assessment, initiatives reported in the literature range from applying existing instruments within the context of higher education, e.g. the ecological footprint to assess campus operations (Lambrechts and Van Liedekerke 2014); adapting existing instruments to be used in higher education, e.g. Global Reporting Initiative (GRI 2011); or developing specific instruments to be used within the framework of higher education, e.g. the Assessment Instrument for Sustainability in Higher Education (AISHE), as described by Roorda (2001).

In describing the different assessment tools and instruments, their position and contribution to the sustainability integration process in higher education is often highlighted as threefold (Lambrechts and Ceulemans 2013):

(1) Sustainability assessment contributes to policy development;

(2) Sustainability assessment contributes to mainstreaming sustainable development in higher education; 
(3) Sustainability assessment contributed to transparency and communication.

Sustainability assessment is seen as an important tool for decision-making in a variety of contexts, as an assessment contributes to understanding the sustainability challenge in a given context, provides information on sustainability impacts and fosters the defining of objectives (Waas et al. 2014). Also in the context of higher education institutions, applying tools for sustainability assessment and (self) reporting, can encourage the planning process for sustainability goals and actions (Lidstone, Wright, and Sherren 2015) or the comparison of different higher education institutions in an attempt to benchmark results (Shriberg 2002). Furthermore, sustainability assessment could be seen as a part of the process of sustainability reporting, however the two terms can clearly be differentiated and defined (Ceulemans, Molderez, and Van Liedekerke 2015, in press).

The specific contribution of sustainability assessment towards sustainable development integration in universities has been reported in various cases (e.g. Mader 2013; Meisch et al. 2015), however Ramos and Pires (2013) state that more research is needed towards the contribution of sustainability assessment to structural organisational change in higher education institutions, in order to foster the contribution of higher education to the sustainability transition (Miller, Muñoz-Erickson, and Redman 2011; Ramos and Pires 2013). Furthermore, as higher education institutions see sustainability as a new way of organising themselves in times of educational reforms towards efficiency, management and control (Wals 2014), the contribution of sustainability assessment to these specific conditions and evolutions is recommended. In this context, the link between sustainability assessment and quality assurance in higher education institutions is seen as an important next step in the sustainable development integration process (Vettori and Rammel 2014).

This article focuses on the first asset of sustainability assessment in higher education described by Lambrechts and Ceulemans (2013), i.e. its contribution towards policy 
development. Section 2 further focuses on tools and instruments to assess sustainability in higher education institutions, with a focus on education, research, outreach and campus operations, their position in the integration of sustainable development in higher education institutions, and a presentation of the AISHE instrument. Section 3 describes the research questions, method and scope of the study. Results of the reflective case are described in section 4. Section 5 presents the discussion, connecting the results of section 4 with previous research on the case. Finally section 6 describes conclusions and recommendations for further research and policy development in higher education.

\section{Sustainability assessment tools}

In recent years, as an answer to the need to define guidelines for sustainability integration in higher education, a variety of sustainability assessment tools have been developed (Shriberg 2004; Siemer, Elmer, and Rammel 2006), each with their own scope (education, research, outreach, campus operations), criteria (qualitative, quantitative), and methods (survey, focus groups, interviews, etc.). Providing an exhaustive overview of existing tools and instruments would stretch far beyond the scope of this article, however, some examples are given in order to demonstrate the variety of approaches in the field. These examples are chosen in an arbitrary manner, based on the reports about these instruments in recent peer reviewed book chapters and articles. The Graphical Assessment for Sustainability in Universities (GASU) provides guidance to assess education, research, outreach and operations in a qualitative and quantitative way. This tool uses desk research as the main method to collect data (Lozano 2006). The Sustainability Tool for Assessing UNiversities' Curricula Holistically

(STAUNCH, RTM) is specifically focusing on education, providing qualitative and quantitative data through desk research methods (Glover, Peters, and Haslett 2011; Lozano 2010). The Sustainability Tracking, Assessment and Rating System (STARS) covers 
education, research, outreach and operations, providing qualitative and quantitative data through desk research and self-reporting methods. The instrument has been developed by the Association for the Advancement of Sustainability in Higher Education (AASHE 2012).

The Auditing Instrument for Sustainability in Higher Education (AISHE) was launched by the Dutch Committee for Sustainable Higher Education, and developed by Roorda (2001). Later on, the name of the instrument was changed to 'Assessment Instrument for Sustainability in Higher Education', still using the same acronym. AISHE is based on a model for quality management, i.e. the European Foundation for Quality Management (EFQM), with the underlying idea that an organisation can be positioned in a certain phase when assessing its performance on a given topic. AISHE defines five phases: (1) Activityoriented; (2) Process-oriented; (3) System-oriented; (4) Chain-oriented; (5) Society-oriented. The assessment process of AISHE is based on twenty criteria, clustered in five groups, as shown in table 1. An AISHE assessment is performed by a group of approximately 15 participants, ranging from teachers, administrative staff, policy makers, students, and if possible external stakeholders. Each of the participants first evaluates the twenty criteria individually, deciding in which phase the higher education institution or study program is situated. Later on, a consensus meeting takes place, in which the group of participants has to reach consensus about the phase of each criterion. The result of an AISHE assessment is a written report, with a graphical representation of the scores of all criteria (Roorda 2001). In 2009, a new version, called AISHE 2.0 was launched, using the same process oriented method, but covering five modules: education, research, societal role (outreach), operations and policy. Furthermore, it provides both qualitative and quantitative data (Roorda et al. 2009).

Since the launch of the instrument in 2001, AISHE has been used in a number of universities worldwide (Roorda 2013), however reports about the experiences with the 
instrument are limited available. The use of AISHE in the light of policy development initiatives was highlighted by Roorda (2004). Further reported cases focus upon the link between assessment and certification (Roorda and Martens 2008). First hand experiences with the instrument are provided by Lambrechts and Ceulemans (2013), reporting about the experiences with the use of AISHE in two Belgian higher education institutions, Leuven University College (KHLeuven) and Hogeschool-Universiteit Brussel (HUB). Based on 15 AISHE assessments in these higher education institutions, they provide an evaluation of the instrument, including strengths, weaknesses, opportunities and threats related to its use. Another case is provided by Brandli et al. (2014), presenting the experiences with AISHE in the University of Passo Fundo (UPF), in which 30 study programs were assessed. The study shows that there is a lack of policy to support sustainability integration in higher education institutions' academic and operational practices (Brandli et al. 2014). The cases reported in the literature point out that, when performing an AISHE assessment, policy development initiatives are regularly mentioned, both within the results of the assessment, as in the possibilities to further integrate sustainable development within the higher education institution.

\section{Research question, method and scope}

Sustainability assessment in higher education is often seen as important because of its (possible) contribution to policy development in higher education institutions. However, this statement is merely made out of the possibilities perspective and less from the perspective of real empirical data on the contribution of the use of sustainability assessment tools and instruments to policy development in higher education institutions. This article starts from the following research questions: 
- Q1: What is the contribution of sustainability assessment to policy development in a higher education institution?

- Q2: How are results of sustainability assessment used and integrated within the policy context of the higher education institution?

In order to find an answer to the two research questions, the grounded theory approach is used (as described by Strauss 1987), in which data are systematically and intensively analysed in an iterative and cyclical process, in order to organise and structure different trends within the concept. In order to do this, this article presents a critical interpretative analysis of sustainability assessment reports of a higher education institution. In order to structure data on the contribution of sustainability assessment, a framework for analysis is drafted using the structure of the model as described by Verhulst and Lambrechts (2015, in press), with a focus on human factors in an organisational change process: (1) organisational culture; (2) resistance against change; (3) empowerment and involvement; (4) internal communication on changes.

This article looks at sustainability assessment and policy development at the level of a single higher education institution, Leuven University College (KHLeuven). Choice for this in-depth case is based on several arguments: first, this higher education institution is the only one in Belgium with a considerable amount of sustainability assessment reports (i.e. more than ten, of which four consecutive), thus providing sufficient data for policy development analysis. Second, this higher education institution has a well-documented history regarding the integration of sustainable development, providing a lot of supplementary materials for analysis. The reports are based on AISHE, and provide structured information based on twenty criteria. The choice for AISHE was made 2003 because of its innovative nature (as described by Shriberg 2002), the specific structure of the instrument (process oriented, based 
on quality management approach) and because the instrument was available in Dutch, which was the working language within the higher education institution (Lambrechts, Van den Haute, and Vanhoren 2009). This availability in different languages improves possibilities to use the instrument at a local level.

The critical iterative process consists of three steps. In a first step, during a first reading of the reports, the described information is categorised and labelled in an open analysis (i.e. without prescriptive parameters). The outcome of this step is a long list of categories discovered in the reports. In a second step, the reports are analysed again with prescriptive parameters derived from the human factors model, thus clustering categories according to their contribution to, or inference with, organisational aspects, barriers against change, stakeholder involvement, and communication on change. In a third step, the categories specifically referring to policy development are interpreted and analysed in depth.

\section{Results}

KHLeuven has performed eleven AISHE audits in the timeframe of 2003-2010. Each study program of the higher education institution has been assessed. Furthermore, the Department of Business Studies performed four different audits in a timespan of seven years, allowing to analyse in depth the evolution of sustainability integration in this particular department. The first AISHE audits in KHLeuven (2003 and 2004) were organised within the framework of a pilot project on the integration of sustainability in business management study programs (marketing, finance and insurance, accountancy and fiscal studies). The audits of 2009 and 2010 were organised as part of the departments' efforts to link sustainability integration with the evaluation and accreditation frameworks. 
Table 1. Results of the AISHE audits in the Department of Business Studies (based on: Lambrechts and Ceulemans 2013).

\begin{tabular}{|c|c|c|c|c|c|c|}
\hline \multirow{2}{*}{ Criterion } & & & \multicolumn{4}{|c|}{ Year } \\
\hline & & & '03 & '04 & '09 & '10 \\
\hline \multirow[t]{4}{*}{ 1. Vision and policy } & 1.1. & Vision & 1 & 3 & 3 & $3 / 4$ \\
\hline & 1.2. & Policy & 2 & 3 & 3 & $3 / 4$ \\
\hline & 1.3. & Communication & 1 & 2 & 3 & $4 / 5$ \\
\hline & 1.4. & Internal environmental management & 1 & 1 & 2 & $2 / 3$ \\
\hline \multirow[t]{4}{*}{ 2. Expertise } & 2.1. & Network & $1 / 2$ & 2 & 2 & $4 / 5$ \\
\hline & 2.2. & Expert group & $1 / 2$ & $2 / 3$ & 3 & $3 / 4$ \\
\hline & 2.3 & Staff development plan & 1 & 2 & 2 & 3 \\
\hline & 2.4. & Research and external services & 1 & 2 & 4 & 4 \\
\hline \multirow{4}{*}{$\begin{array}{l}\text { 3. Educational goals and } \\
\text { methodology }\end{array}$} & 3.1. & Profile of the graduate & 1 & $2 / 3$ & $3 / 4$ & $3 / 4$ \\
\hline & 3.2. & Educational methodology & 2 & 2 & $3 / 4$ & 3 \\
\hline & 3.3. & Role of the teacher & 1 & $1 / 2$ & 3 & $3 / 4$ \\
\hline & 3.4. & Student examination & 1 & 1 & 2 & $2 / 3$ \\
\hline \multirow[t]{4}{*}{ 4. Educational context } & 4.1. & Curriculum & 1 & $1 / 2$ & 2 & $2 / 3$ \\
\hline & 4.2. & Integrated problem handling & 1 & 2 & 3 & 3 \\
\hline & 4.3. & Traineeship, graduation & 1 & 2 & 3 & 3 \\
\hline & 4.4. & Speciality & 0 & 0 & 2 & $2 / 3$ \\
\hline \multirow[t]{4}{*}{ 5. Result assessment } & 5.1. & Staff & 0 & 0 & 2 & 3 \\
\hline & 5.2. & Students & 0 & 0 & 2 & 3 \\
\hline & 5.3. & Professional field & 1 & 1 & 1 & 3 \\
\hline & 5.4 & Society & 0 & 0 & 1 & 2 \\
\hline
\end{tabular}

\section{Descriptive analysis of the data}

Analysing the four consecutive AISHE audits of the Department of Business Studies, allows an in depth interpretation of the results, and describing trends in results and contributions to the policy development in the organisation. The AISHE audit results provide a clear score for each criterion, as achieved by consensus between the participants of the audits. Score 1 means 
that the criterion is 'activity-oriented', score 2 stands for 'process-oriented', score 3 goes on with 'system-oriented', followed by score 4 'chain-oriented' and score 5 'society-oriented'. Table 1 and Figure 1 both provide an overview of the results (scores) of the four AISHE audits in the Department of Business Studies.

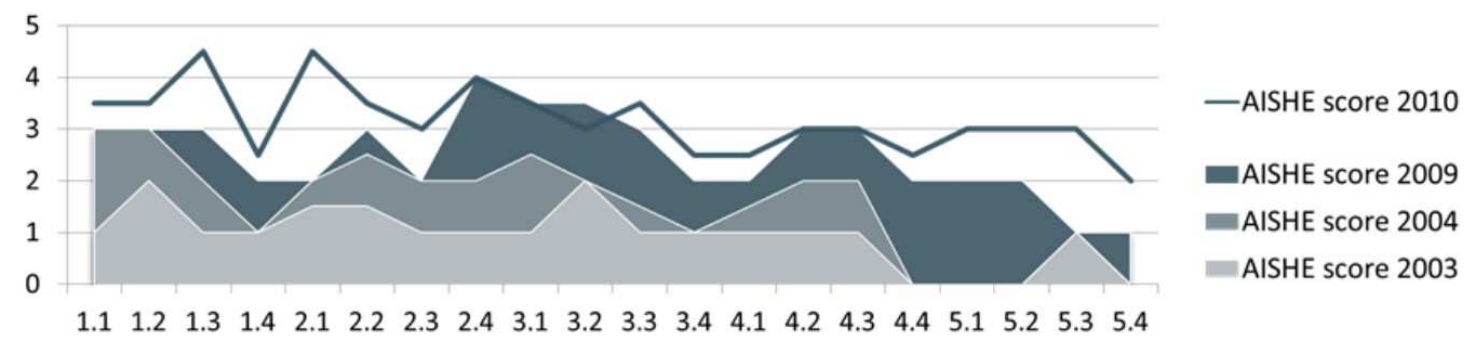

Figure 1. Results of the AISHE audits in the Department of Business Studies (based on: Lambrechts and Ceulemans 2013)

\section{The sustainability integration process as described within the AISHE reports}

The AISHE reports contain elaborate information about the current situation and desired situation of twenty criteria. Moreover, looking at the four subsequent reports of KHLeuven, information about the sustainability integration process can be detected and analysed. Table 2 provides an overview of the content of the assessment reports, in the form of key messages for each of the twenty criteria. A closer look at the written reports reveals that the description of the criteria evolves from the majority being 'ad hoc' initiatives in the 2003 and 2004 reports, to a more systemic and structural approach in the 2009 and 2010 reports. Figure 2 provides a graph depicting this evolution. It shows the number of criteria within the AISHE reports referred to in a specific way. The 2003 report mainly refers to elements that can be categorised as 'not available, not visible, implicit, ad hoc' etc., while the 2004 report already makes reference to systematic, explicit initiatives, although still project based. The 2009 and 2010 reports contain a high amount of references towards the categories explicit and systematic. However, what is striking in this analysis, is the re-appearance of individual 
initiatives in the 2010 report, indicating that, although in some criteria a systemic approach is

reported upon, a stagnation is taking place in the sustainability integration process.

Table 2. Key messages of the AISHE reports.

\begin{tabular}{|c|c|c|c|c|}
\hline AISHE Criterion & 2003 & 2004 & 2009 & 2010 \\
\hline 1.1. Vision & $\begin{array}{l}\text { "elements are } \\
\text { integrated" } \\
\text { "implicit" }\end{array}$ & $\begin{array}{l}\text { "is integrated } \\
\text { explicitly" }\end{array}$ & $\begin{array}{l}\text { "vision both at } \\
\text { departmental level } \\
\text { and university college } \\
\text { level" } \\
\text { "stakeholder } \\
\text { involvement" }\end{array}$ & $\begin{array}{l}\text { "four different texts } \\
\text { on SD vision are } \\
\text { available" }\end{array}$ \\
\hline 1.2. Policy & $\begin{array}{l}\text { "rather implicit" } \\
\text { "not visible" }\end{array}$ & $\begin{array}{l}\text { "policy is available } \\
\text { through project" }\end{array}$ & $\begin{array}{l}\text { "university college } \\
\text { wide policy plan, } \\
\text { translated at the } \\
\text { departmental level" }\end{array}$ & $\begin{array}{l}\text { "different internal } \\
\text { and external } \\
\text { stakeholders are } \\
\text { informed, but mainly } \\
\text { informal" }\end{array}$ \\
\hline 1.3. Communication & $\begin{array}{l}\text { "rather incidental" } \\
\text { "not systematic" }\end{array}$ & $\begin{array}{l}\text { "limited, ad hoc and } \\
\text { not systematically" }\end{array}$ & $\begin{array}{l}\text { "variety of } \\
\text { initiatives" }\end{array}$ & $\begin{array}{l}\text { "very strong internal } \\
\text { and external } \\
\text { communication" }\end{array}$ \\
\hline $\begin{array}{l}\text { 1.4. Environmental } \\
\text { care }\end{array}$ & "some initiatives" & "ad hoc initiatives" & $\begin{array}{l}\text { "a lot of initiatives by } \\
\text { HSE-comite" }\end{array}$ & $\begin{array}{l}\text { "HSE-comite drafted } \\
\text { an EMS, however not } \\
\text { yet operational" }\end{array}$ \\
\hline 2.1. Network & $\begin{array}{l}\text { "individual } \\
\text { initiatives" } \\
\text { "not embedded" }\end{array}$ & $\begin{array}{l}\text { "embedded quite } \\
\text { systematically" }\end{array}$ & "rather project based" & $\begin{array}{l}\text { "strong commitment } \\
\text { in different local and } \\
\text { regional networks" }\end{array}$ \\
\hline 2.2. Expert-group & $\begin{array}{l}\text { "should be better } \\
\text { positioned" }\end{array}$ & $\begin{array}{l}\text { "group of experts } \\
\text { based on a single } \\
\text { project" }\end{array}$ & $\begin{array}{l}\text { "group of colleagues, } \\
\text { mainly oriented } \\
\text { towards education" }\end{array}$ & $\begin{array}{l}\text { "experts are mainly } \\
\text { project-based and } \\
\text { with external focus" }\end{array}$ \\
\hline $\begin{array}{l}\text { 2.3. Staff } \\
\text { Development }\end{array}$ & "ad hoc" & $\begin{array}{l}\text { "ad hoc initiatives" } \\
\text { "not systematically } \\
\text { embedded" }\end{array}$ & "several initiatives" & $\begin{array}{l}\text { "professionalisation } \\
\text { activities for staff" }\end{array}$ \\
\hline 2.4. Research & $\begin{array}{l}\text { "ad hoc" } \\
\text { "based on single } \\
\text { projects or } \\
\text { initiatives" }\end{array}$ & $\begin{array}{l}\text { "more and more } \\
\text { initiatives" } \\
\text { "still ad hoc" }\end{array}$ & $\begin{array}{l}\text { "at the level of the } \\
\text { university college, } \\
\text { SD is prior focus" }\end{array}$ & $\begin{array}{l}\text { "policy for research } \\
\text { with different } \\
\text { elements of SD" }\end{array}$ \\
\hline $\begin{array}{l}\text { 3.1. Profile of } \\
\text { graduate }\end{array}$ & $\begin{array}{l}\text { "elements available" } \\
\text { "lecturers ask for a } \\
\text { set of competences" }\end{array}$ & $\begin{array}{l}\text { "general competences } \\
\text { available, room for } \\
\text { SD" }\end{array}$ & $\begin{array}{l}\text { "competences for SD } \\
\text { are (partially) } \\
\text { available" }\end{array}$ & $\begin{array}{l}\text { "elements in } \\
\text { competence } \\
\text { matrices" }\end{array}$ \\
\hline $\begin{array}{l}\text { 3.2. Educational } \\
\text { methodology }\end{array}$ & $\begin{array}{l}\text { "elements are } \\
\text { available" }\end{array}$ & $\begin{array}{l}\text { "elements are } \\
\text { available" }\end{array}$ & $\begin{array}{l}\text { "strong focus on } \\
\text { critical reflection" }\end{array}$ & $\begin{array}{l}\text { "different initiatives" } \\
\text { "not structurally" }\end{array}$ \\
\hline 3.3. Role of teacher & $\begin{array}{l}\text { "based on interest } \\
\text { and goodwill of } \\
\text { individuals" }\end{array}$ & $\begin{array}{l}\text { "ad hoc" } \\
\text { "some elements of } \\
\text { structural approach" }\end{array}$ & $\begin{array}{l}\text { "5 key competences } \\
\text { for staff" }\end{array}$ & $\begin{array}{l}\text { "different elements } \\
\text { available" } \\
\text { "not structurally" }\end{array}$ \\
\hline 3.4. Assessment & $\begin{array}{l}\text { "ad hoc" } \\
\text { "at the level of } \\
\text { individuals" } \\
\text { "incidental" }\end{array}$ & $\begin{array}{l}\text { "available in some } \\
\text { courses" }\end{array}$ & $\begin{array}{l}\text { "still ad hoc" } \\
\text { "depends on } \\
\text { individual initiatives" }\end{array}$ & $\begin{array}{l}\text { "ad hoc" } \\
\text { "assessment policy is } \\
\text { still in its early } \\
\text { development" }\end{array}$ \\
\hline 4.1. Curriculum & "singular cases" & $\begin{array}{l}\text { "list of initiatives, } \\
\text { however SD has no } \\
\text { place at the start of } \\
\text { the study program" }\end{array}$ & $\begin{array}{l}\text { "SD explicitly } \\
\text { integrated in some } \\
\text { courses" }\end{array}$ & $\begin{array}{l}\text { "available in some } \\
\text { courses" } \\
\text { "however not } \\
\text { structurally } \\
\text { embedded" }\end{array}$ \\
\hline
\end{tabular}




\begin{tabular}{|c|c|c|c|c|}
\hline $\begin{array}{l}\text { 4.2.Integrated } \\
\text { problem handling }\end{array}$ & $\begin{array}{l}\text { "available, however } \\
\text { not connected to SD" }\end{array}$ & "strong initiatives" & $\begin{array}{l}\text { "is a focus point in } \\
\text { our study program" }\end{array}$ & $\begin{array}{l}\text { "a lot of initiatives } \\
\text { and examples" }\end{array}$ \\
\hline 4.3.Traineeships & $\begin{array}{l}\text { "SD is seldom } \\
\text { available" }\end{array}$ & $\begin{array}{l}\text { "concrete } \\
\text { possibilities within a } \\
\text { single project" }\end{array}$ & $\begin{array}{l}\text { "several initiatives" } \\
\text { "no structural } \\
\text { approach" }\end{array}$ & $\begin{array}{l}\text { "through integration } \\
\text { assignment, fixed } \\
\text { part of curriculum" }\end{array}$ \\
\hline 4.4.Specialisation & "not available" & $\begin{array}{l}\text { "not available" } \\
\text { "possible in future" }\end{array}$ & $\begin{array}{l}\text { "general course on } \\
\text { SD" } \\
\text { "other initiatives" }\end{array}$ & $\begin{array}{l}\text { "different } \\
\text { possibilities are } \\
\text { available" }\end{array}$ \\
\hline 5.1.Staff & "no focus on SD" & "not applicable" & $\begin{array}{l}\text { "SPA-surveys" } \\
\text { "trend data through } \\
\text { AISHE audits" }\end{array}$ & $\begin{array}{l}\text { "SPA-surveys, } \\
\text { interim reporting of } \\
\text { policy at } \\
\text { departmental level, } \\
\text { benchmarking" }\end{array}$ \\
\hline 5.2.Students & "no focus on SD" & "not applicable" & $\begin{array}{l}\text { "SPA-surveys" } \\
\text { "trend data through } \\
\text { AISHE audits" }\end{array}$ & $\begin{array}{l}\text { "SPA-surveys, } \\
\text { evaluation of SD } \\
\text { courses" }\end{array}$ \\
\hline 5.3.Professional field & $\begin{array}{l}\text { "initiative within the } \\
\text { framework of a single } \\
\text { project" }\end{array}$ & $\begin{array}{l}\text { "initiative within the } \\
\text { framework of a single } \\
\text { project" }\end{array}$ & $\begin{array}{l}\text { "data available from } \\
\text { different sources" } \\
\text { "no trend data" }\end{array}$ & $\begin{array}{l}\text { "surveys of graduates } \\
\text { and alumni, external } \\
\text { organisations, also } \\
\text { focus on SD" }\end{array}$ \\
\hline 5.4.Society & "no data available & "not applicable" & $\begin{array}{l}\text { "data available } \\
\text { through informal } \\
\text { contacts" }\end{array}$ & $\begin{array}{l}\text { "qualitative } \\
\text { information through } \\
\text { informal contacts" }\end{array}$ \\
\hline
\end{tabular}

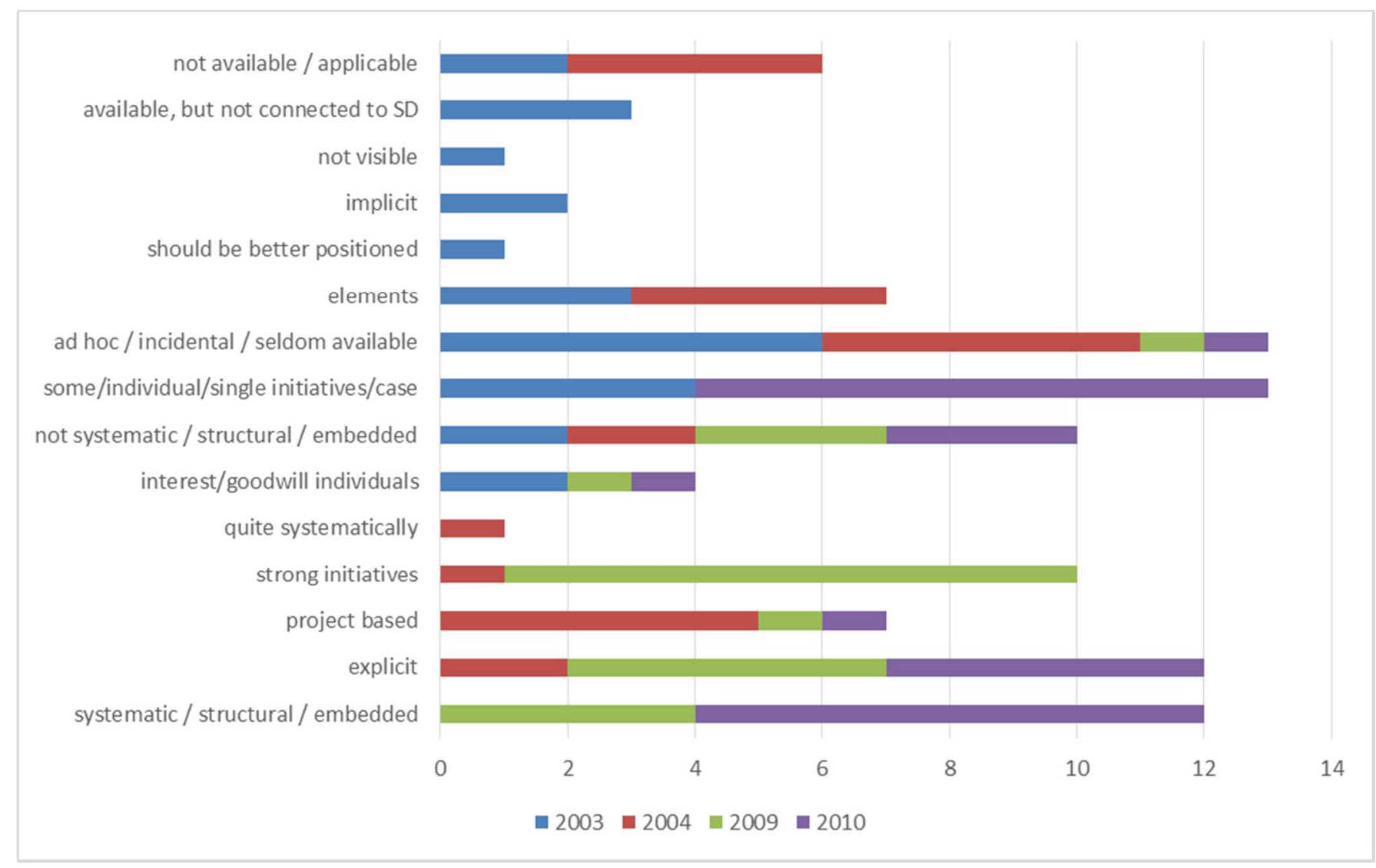

Figure 2. Description of criteria in the AISHE reports 


\section{Possible contribution to policy development}

In order to find out how and to what extent the process of undergoing an AISHE assessment contributes to the policy development in the case, the content of the four AISHE reports are analysed in depth, focusing on elements referring to policy development (in general) or connecting the AISHE criteria to ongoing policy developments (specific). Each of the four AISHE reports contained references to policy development initiatives, planned to take place in the near future, or already undertaken within the case. Table 3 presents some examples of different references to policy development initiatives within the AISHE reports.

Table 3. References to policy development in the AISHE reports.

\begin{tabular}{|l|l|l|l|l|}
\hline Level & Type & Quote & $\begin{array}{l}\text { AISHE } \\
\text { report }\end{array}$ & $\begin{array}{l}\text { AISHE } \\
\text { criterion }\end{array}$ \\
\hline $\begin{array}{l}\text { Micro / } \\
\text { departmental }\end{array}$ & General vision / policy & $\begin{array}{l}\text { 'different elements of SD are } \\
\text { (sometimes implicit) integrated in } \\
\text { the vision of the department and in } \\
\text { supporting documents' }\end{array}$ & 2003 & 1.1. \\
\cline { 2 - 5 } & $\begin{array}{l}\text { Specific vision / policy } \\
\text { 'a specific vision on SD is defined } \\
\text { at the departmental level' }\end{array}$ & 2004 & 1.1. \\
\hline $\begin{array}{l}\text { Meso / University } \\
\text { college wide }\end{array}$ & $\begin{array}{l}\text { Specific vision / policy } \\
\text { on SD }\end{array}$ & $\begin{array}{l}\text { 'the vision is defined both at the } \\
\text { level of the university college, as at } \\
\text { the level of the department'. } \\
\text { 'four different texts concerning } \\
\text { vision are available [i.e. university } \\
\text { college wide, departmental, } \\
\text { educational vision, vision on } \\
\text { Health, Safety and Environment } \\
\text { (HSE)]' }\end{array}$ & 2009 & 1.1. \\
\hline $\begin{array}{l}\text { Macro / External } \\
\text { factors }\end{array}$ & Visitation / accreditation & $\begin{array}{l}\text { 'continue the efforts [concerning } \\
\text { evaluation by external } \\
\text { stakeholders], and connect with the } \\
\text { self-assessment report, to be drafted } \\
\text { in 2007 in preparation of the } \\
\text { visitation' }\end{array}$ & $2003 \&$ & 5.3. \\
\hline
\end{tabular}

A first group of contribution to policy development is direct influence of the AISHE audit to the policy development at micro-level (i.e. the level of the study program or department). The 
effect of this type of contribution to policy development is most obvious in AISHE-criteria 1.1. and 1.2., focusing respectively on 'vision' and 'policy'. Regarding 1.1. Vision, the AISHE report of 2003 states that 'different elements of sustainable development are (sometimes implicit) integrated in the vision of the department and in supporting documents'. The AISHE report of 2004, intended as a follow-up of the 2003 assessment, clearly refers to the explicit departmental vision on sustainable development, as was drafted following to the 2003 AISHE assessment. This vision was a policy development initiative at the departmental level (Verhulst and Lambrechts 2015, in press). In the years after the second AISHE report, a university college college wide vision on sustainable development was drafted, which is an initiatives at meso-level.

A second group of initiatives contributing to policy development are situated at the meso-level, referring to the university college wide level. The AISHE report of 2009 refers to this type, concerning the criterion 1.1. 'Vision': 'the vision is defined both at the level of the university college, as at the level of the department'. The 2010 AISHE report states that 'four different texts concerning vision are available [i.e. university college wide, departmental, educational vision, vision on Health, Safety and Environment (HSE)]'.

A third group of initiatives are situated at macro-level, and refer to external stakeholders or factors influencing policy development in the higher education institution. This kind of elements can be found in a variety of criteria, but mainly come into sight in criteria concerning quality assurance. The AISHE reports of 2003 and 2004, in describing the 'desired situation' for criteria concerning assessment, both refer to the accreditation process: 'continue the efforts [concerning evaluation by external stakeholders], and connect with the self-assessment report, to be drafted in 2007 in preparation of the visitation'. Furthermore, the 2009 and 2010 AISHE assessments were also seen as preparatory (self) assessments in light of the upcoming visitation and accreditation process of 2011. These examples point to the 
potential of the AISHE instrument to contribute to policy development in light of external influencing factors.

\section{Discussion}

The higher education institution focused upon in this article, offers an elaborate case for the integration process of sustainable development. In this discussion section, the insights derived from the analysis of the AISHE reports are connected to the results of an elaborate study on the general implementation process in the same higher education institution, from a change management perspective, as reported by Verhulst and Lambrechts (2015, in press). In this study, the sustainability implementation process at KHLeuven was analysed using a human factors model, and empirical data from 2003-2013. The discussion is based on three elements: (1) the connection between sustainability assessment and policy development initiatives in the higher education institution; (2) the interlinking of sustainability assessment and the general sustainability implementation process; (3) the appearance of human factors in sustainability assessment reports.

The insights from the AISHE reports show that a lot of policy development initiatives are mentioned, both in describing the current situation as in describing the desired situation. Based on the four reports, information is available for 2003, 2004, 2009 and 2010, however, not all prospected plans and desired situation descriptions are touched upon in following reports. Here the elaborate study reported by Verhulst and Lambrechts (2015, in press) can provide the missing information to complete the picture on sustainability assessment and policy development in this higher education institution. The analysis of the AISHE reports shows the evolution of drafting a vision and policy plan, first at departmental level (microlevel), in later years also at university college wide level (meso-level). The reports also show an evolution on two tracks: (1) drafting an explicit and exclusive vision and policy plan for 
sustainable development; and (2) integrating sustainable development in other policy plans, e.g. the vision on education, the general key competences for employees, and het HSE-plan. In the reports, this seems like a perfect situation, where bottom-up initiatives are picked up by a top-down approach. These results are also confirmed by the study of Verhulst and Lambrechts (2015, in press), however the message is more multifaceted: bottom-up initiatives were indeed picked-up by a top-down approach, however they were not implemented properly within the structure of the higher education institution, leading to partial integration of the topic, and more worse, demotivation and sustainability-fatigue with the employees originally working on the topic. This leads to the impression that sustainability assessment in general and AISHE in particular could indeed lead to policy development initiatives, however more efforts are needed to thoroughly implement these initiatives within the higher education institutions' structure. It confirms the findings in the literature that applying an assessment instrument is only one element in the process of policy development (Waas et al. 2014). It also confirms the findings of Brandli et al. (2014) that more policy support is needed after a sustainability assessment.

The AISHE reports contain a lot of information regarding drivers, barriers, and other influencing factors of the sustainability integration process. The analysis showed references made towards single (pilot-)projects, possibilities to link AISHE criteria with general processes in the higher education institution, and obstacles that prevent further integration. These factors could be linked and compared to the human factors, as described by Verhulst and Lambrechts (2015, in press) as organisational culture; resistance against change; empowerment and involvement; internal communication on changes. By far the human factor with the highest influence mentioned in the AISHE reports is 'communication', although the importance of this factors is sometimes contested within the reports (see on this issue: Lambrechts and Ceulemans 2013). Resistance against change is also reported on in the 
AISHE reports, mainly regarding the criteria 3.3. 'Role of teacher' and 3.4. 'Assessment', in both cases the reports point to the individual initiative and goodwill of teachers. Regarding the factor 'empowerment and involvement', the AISHE reports reflect on the specific involvement of both internal and external stakeholders, with special attention towards students. The factor 'organisational culture' is also present within the AISHE reports, mainly pointing towards the specific culture at the higher education institution, focusing on debate and involvement of employees and students, thus providing a connection between bottom-up and top-down approach.

\section{Conclusions and recommendations}

This article started from a specific statement in the literature, i.e. that sustainability assessment of a higher education institutions' education, research, outreach and/or campus operations, has a positive influence on policy development within the organisation. This statement is often made, however seldom with actual reference to empirical data from the field. As KHLeuven has extended experience with sustainability assessment, using the AISHE instrument, this article tried to find evidence for the statement from a practice based approach. The data, available from four different AISHE reports in the Department of Business Studies, provided information on the experiences and process of sustainability integration.

Furthermore, additional data are available through the elaborate case on human factors in the sustainability implementation process, as reported by Verhulst and Lambrechts (2015, in press). The article tries to answer the question whether the AISHE audits really did contribute to the policy development $(\mathrm{Q} 1)$ and how the results of the assessments were integrated within the policy context (Q2). Analysis of the data showed some remarkable elements, and a complex situation, leading towards a much more nuanced answer that can hardly be comprised in a 'yes' or 'no'. 
Regarding Q1, a first conclusion drawn from the analysis of the AISHE reports shows that it is hard to talk about 'policy development' as 'one' concept within 'one' higher education institution. It is rather a multi-leveled concept, influenced by a variety of internal and external factors. The different AISHE reports mention three levels of policy development: micro-level or departmental level, in this case the Department of Business Studies; meso-level or university college wide level, in this case embodied by the overarching level of general policy and services; macro-level, in this case the Dutch-Flemish Accreditation Organisation, responsible for visitation of study programs and thus influencing policy development at meso- and micro-level. The contribution of AISHE to each of these types of policy development is threefold: (1) encouraging and kick-starting the drafting of a specific vision and policy plan for sustainable development, first at micro-level, later at meso-level; (2) the integration of elements of sustainable development within the existing processes of the higher education institution, in particular the quality assurance framework at meso-level; (3) providing input for the self-assessment reports to be drafted as a preparation of the visitation and accreditation process. However, the AISHE reports of 2009 and 2010 also show a stagnation after some years, as some criteria still are not embedded structurally, or initiatives mentioned in 2003 and 2004 did not continue. This conclusion is relevant to other higher education institutions, depending on their profile and structure (centralised or decentralised), and the specific regional conditions (e.g. accreditation guidelines). It shows that higher education institutions should consider to acknowledge specific conditions when performing a sustainability assessment, as the different levels and influencing factors of policy development are determining the goals and process of assessment in the organisation. Furthermore, this leads to the specific recommendation to other higher education institutions to acknowledge the importance of continuing attention to the sustainability integration process, and to the possibilities as to integrate and link elements of sustainability assessment 
within quality assurance frameworks within the specific higher education institution.

Regarding the validity and effectiveness of the AISHE tool, the reports show an evolution in sustainability integration which was also discovered through other sources as described by Verhulst and Lambrechts (2015, in press). Furthermore, the findings approve earlier results reported in Lambrechts and Ceulemans (2013), stating that the quality management structure of AISHE is an asset, whereas the scope (i.e. a single study program) and subjective experiences might bias results.

Regarding Q2, the analysis shows a gradual process in which the bottom-up, individual initiatives are leading towards collective, top-down actions. However, the AISHE report of 2010 clearly shows the importance of individual projects and initiatives again, rather than a structural approach of embedding sustainable development within the organisations' structure and policy. This gives the impression that the AISHE reports indeed contributed to policy development initiatives, but that this particular higher education institution did not (yet) succeed in structurally embedding the topic within the organisation, thus leading to a point of stagnation or even a fallback to individual initiatives. These findings could be relevant for other higher education institutions thinking about using sustainability assessment, providing food for thought on which process the higher education institution is envisioning: guiding a general sustainability integration process or rather using the assessment as a tool to report about initiatives to external parties. The AISHE assessments indeed contribute to certain elements of policy development, but a more structural support of the organisation is needed to ensure a systemic organisational incorporation of sustainable development. In other words, to be effective, setting all hopes on a single sustainability assessment to encourage policy development for sustainability in a particular higher education institution, should be combined with a strong and clear commitment of policy makers, in order to lead to successful integration of sustainable development. 
The scope and approach in this article also have some limitations. A first limitation concerns the type of sources used for the analysis. Although the assessment reports provide detailed information on the results of the assessments and the perceptions of assessment participants, it might not show the full state of policy development at a given moment, or omit detailed information on the initiatives referred to in the reports. Within this study, the specific higher education institution has an extensive body of reports available on the general sustainability integration process, which could be used to check and validate results of the iterative analysis process. Second, the choice for a single case study is often seen as a limitation regarding the transferability of results. However, given the topic of sustainability assessment in higher education, and more specifically its contribution to the general sustainability integration process within higher education institutions, there is still a need for in-depth cases. It is recommended that the same process would be analysed in other higher education institutions, whether they have used AISHE or other assessment instruments, in order to validate results and further elaborate on the topic.

\section{Acknowledgements}

This article is based on the experiences with AISHE within Leuven University College. The author would like to thank all colleagues involved in the different AISHE meetings and initiatives, and for their valuable input and support for this publication.

\section{References}

Association for the Advancement of Sustainability in Higher Education (AASHE). 2013. The Sustainability Tracking, Assessment \& Rating System ${ }^{\mathrm{TM}}$ - STARS 2.0 Technical Manual. https://stars.aashe.org/. 
Brandli, L., Frandoloso, M., Roorda, N., Fraga, K., and L. Vieira. 2014. "Evaluation of sustainability using the AISHE instrument: case study in a Brazilian University." Brazilian Journal of Science and Technology (1) 4: 1-13.

Ceulemans, K., Molderez, I., and L. Van Liedekerke. 2015, in press. "Sustainability reporting in higher education: a comprehensive review of the recent literature and paths for further research.” Journal of Cleaner Production. doi:10.1016/j.jclepro.2014.09.052.

Global Reporting Initiative (GRI). 2011. Sustainability Reporting Guidelines. Version 3.1. Amsterdam: GRI. https://www.globalreporting.org/resourcelibrary/G3.1-Guidelines-InclTechnical-Protocol.pdf.

Glover, A., Peters, C., and S.K. Haslett. 2011. "Education for sustainable development and global citizenship: An evaluation of the validity of the STAUNCH auditing tool." International Journal of Sustainability in Higher Education 12 (2): 125-144.

Lambrechts, W., Van den Haute, H., and I. Vanhoren. 2009. Duurzaam hoger onderwijs. Appel voor verantwoord onderrichten, onderzoeken en ondernemen. [Sustainable Higher Education. Appeal for Responsible Education, Research and Operations]. Leuven: LannooCampus.

Lambrechts, W., Mulà, I., Ceulemans, K., Molderez, I., and V. Gaeremynck. 2013. "The integration of competences for sustainable development in higher education: an analysis of bachelor programs in management.” Journal of Cleaner Production 48: 65-73.

Lambrechts, W., and Ceulemans, K. 2013. "Sustainability Assessment in Higher Education. Evaluating the Use of the Auditing Instrument for Sustainability in Higher Education (AISHE) in Belgium”. In Sustainability Assessment Tools in Higher Education Institutions. Mapping Trends and Good Practice Around the World, edited by Caeiro, S., Leal Filho, W., Jabbour, C., and U. Azeiteiro, 157-174. Cham, Switzerland: Springer International Publishing. 
Lambrechts, W., and L. Van Liedekerke. 2014. "Using ecological footprint analysis in higher education: Campus operations, policy development and educational purposes." Ecological Indicators 45: 402-406.

Lidstone, L., Wright, T., and K. Sherren. 2015. "Canadian STARS-Rated Campus Sustainability Plans: Priorities, Plan Creation and Design.” Sustainability 7: 725-746.

Lozano, R. 2006. "A tool for a graphical assessment of sustainability in universities (GASU)." Journal of Cleaner Production 14: 963-972.

Lozano, R. 2010. “Diffusion of sustainable development in universities' curricula: An empirical example from cardiff university." Journal of Cleaner Production 18: 637-644.

Lozano, R., Lukman, R., Lozano, F.J., Huisingh, D., and W. Lambrechts. 2013. "Declarations for sustainability in higher education: becoming better leaders, through addressing the university system.” Journal of Cleaner Production 48: 10-19.

Lozano, R., Ceulemans, K., Alonso-Almeida, M., Huisingh, D., Lozano, F.J., Waas, T., Lambrechts, W., Lukman, R., and J. Hugé. 2015, in press. A review of commitment and implementation of Sustainable Development in Higher Education: Results from a worldwide survey. Journal of Cleaner Production. doi:10.1016/j.jclepro.2014.09.048.

Mader, C. 2013. "Sustainability process assessment on transformative potentials: the Graz Model for integrative development." Journal of cleaner production 49: 54-63.

Meisch, S., Hagemann, N., Geibel, J., Gebhard, E., and M.A. Drupp. 2015. "Indicator-Based Analysis of the Process Towards a University in Sustainable Development: A Case Study of the University of Tübingen (Germany)." In Integrative Approaches to Sustainable Development at University Level, edited by Leal Filho, W., Brandli, L., Kuznetsova, O. and A.M.F. do Paço, 169-183. Cham, Switzerland: Springer International Publishing.

Miller, T. R., Muñoz-Erickson, T., and C.L. Redman. 2011. “Transforming knowledge for sustainability: towards adaptive academic institutions." International Journal of Sustainability in Higher Education 12 (2): 177-192. 
Ramos, T., and S.M. Pires. 2013. "Sustainability assessment: the role of indicators." In Sustainability Assessment Tools in Higher Education Institutions. Mapping Trends and Good Practice Around the World, edited by Caeiro, S., Leal Filho, W., Jabbour, C., and U. Azeiteiro, 81-99. Cham, Switzerland: Springer International Publishing.

Rieckmann, M. 2012. "Future-oriented higher education: Which key competencies should be fostered through university teaching and learning?" Futures 44 (2): 127-135.

Roorda, N. 2001. Auditing Instrument for sustainability in higher education. Amsterdam: DHO Nederland.

Roorda, N. 2004. "Policy development for sustainability in higher education results of AISHE audits." In Higher education and the challenge of sustainability. Problematics, Promise and Practice, edited by Corcoran, P.B., and A.E.J. Wals, 305-318. Dordrecht: Kluwer Academic Publishers.

Roorda, N. 2013. "A strategy and a toolkit to realize System Integration of Sustainable Development (SISD)". In Sustainability Assessment Tools in Higher Education Institutions. Mapping Trends and Good Practice Around the World, edited by Caeiro, S., Leal Filho, W., Jabbour, C., and U. Azeiteiro, 109-119. Cham, Switzerland: Springer International Publishing.

Roorda, N. and P. Martens. 2008. "Assessment and Certification of Higher Education for Sustainable Development.” Sustainability: The Journal of Record 1 (1): 41-56.

Roorda, N., Rammel, C., Waara S., and U. Fra Paleo. 2009. AISHE 2.0 Manual: Assessment Instrument for Sustainability in Higher Education, Edition 2.0. (Second draft). https://www.box.net/s/0dglhugzyyzta4kkfb83.

Shriberg, M. 2002. "Institutional assessment tools for sustainability in higher education: strengths, weaknesses, and implications for practice and theory.” Higher Education Policy 15 (2): 153-167. 
Shriberg. M. 2004. “Assessing sustainability: Criteria, tools and implications.” In Higher education and the challenge of sustainability. Problematics, Promise and Practice, edited by Corcoran, P.B., and A.E.J. Wals, 71-86. Dordrecht: Kluwer Academic Publishers.

Siemer, S., Elmer, S., and C. Rammel. 2006. Pilot study: Indicators of an education for sustainable development. Vienna: FORUM Umweltbildung.

Strauss, A. 1987. Qualitative Analysis for Social Scientists. New York: Cambridge University Press.

Verhulst, E. and W. Lambrechts. 2015, in press. Fostering the incorporation of SD into the university system. Lessons learned from a change management perspective, Journal of Cleaner Production. doi:10.1016/j.jclepro.2014.09.049.

Vettori, O. and C. Rammel. 2014. "Linking Quality Assurance and ESD: Towards a Participative Quality Culture of Sustainable Development in Higher Education.” In Sustainable Development and Quality Assurance in Higher Education. Transformation of Learning and Society, edited by Fadeeva, Z., Galkute, L., Mader, C., and G. Scott, 49-65. Hampshire: Palgrave Macmillan.

Waas, T., Hugé, J., Block, T., Wright, T., Benitez-Capistros, F., and A. Verbruggen. 2014. "Sustainability Assessment and Indicators: Tools in a Decision-Making Strategy for Sustainable Development." Sustainability 6: 5512-5534.

Wals, A. E. 2014. "Sustainability in higher education in the context of the UN DESD: a review of learning and institutionalization processes." Journal of Cleaner Production 62: 815.

Wiek, A., Withycombe, L., and C.L. Redman. 2011. "Key competencies in sustainability: a reference framework for academic program development." Sustainability Science 6: 203-218.

Wright, T. 2004. “The evolution of sustainability declarations in higher education.” In Higher education and the challenge of sustainability. Problematics, Promise and Practice, edited by Corcoran, P.B., and A.E.J. Wals, 7-20. Dordrecht: Kluwer Academic Publishers. 